\title{
Efektivitas Pembelajaran Matematika dengan Metode Thinking Aloud Pair Problem Solving (TAPPS) Terhadap Hasil Belajar Siswa Pokok Bahasan Kubus dan Balok Kelas VIII SMP/MTs
}

\author{
Vera Mandailina ${ }^{1}$, Mahsup $^{2}$ \\ ${ }^{1,2}$ Pendidikan Matematika, Universitas Muhammadiyah Mataram, Indonesia \\ ${ }^{1}$ vrmandailina@gmail.com, ${ }^{2}$ supyeka@gmail.com
}

\section{INFO ARTIKEL}

Riwayat Artikel:

Diterima: 03-08-2018

Disetujui: 09-10-2018

\section{Kata Kunci:}

Pembelajaran

Matematika, Thinking

Aloud Paor Problem

Solving (TAPPS), Hasil

Belajar

\begin{abstract}
ABSTRAK
Abstrak: Penelitian ini bertujuan untuk mengetahui efektivitas metode pembelajaran Thinking Aloud Pair Problem Solving (TAPPS) terhadap hasil belajar siswa kelas VIII SMP. Jenis penelitian yang digunakan adalah quasi eksperimen dengan melibatkan 42 siswa yang terdiri dari dua kelas dengan teknik purposive sampling. Teknik pengumpulan data dilakukan melalui tes hasil belajar. Teknik analisis data yang dilakukan adalah uji prasyarat analisis dengan uji normalitas, uji homogenitas, dan uji hipotesis dengan uji-t. Berdasarkan analisis data hasil belajar diperoleh rata-rata hasil belajar kelas eksperimen $(51,77)$ lebih tinggi dari pada rata-rata kelas kontrol $(39,95)$. Pada uji normalitas dan homogenitas juga diketahui bahwa kelas eksperimen dan kelas kontrol berdistribusi normal dan homogen. Setelah dilakukan uji-t diperoleh nilai thitung sebesar 2,33 sedangkan tabel pada taraf signifikan 0,05 sebesar 1,684. Karena thitung $>$ tabel, maka $\mathrm{H}_{0}$ ditolak dan $\mathrm{H}_{1}$ diterima. Jadi, dapat ditarik suatu kesimpulan bahwa metode Thinking Aloud Pair Problem Solving (TAPPS) efektif terhadap hasil belajar siswa pada pokok bahasan kubus dan balok kelas VIII SMP.
\end{abstract}

\begin{abstract}
This study aims to determine the effectiveness of the Thinking Aloud Pair Problem Solving (TAPPS) learning method on student learning outcomes in class 8 of Junior High School. The type of research used was quasi-experiment involving 42 students consisting of two classes with purposive sampling technique. Data collection techniques are carried out through learning outcomes tests. The data analysis technique performed is an analysis prerequisite test with normality test, homogeneity test, and hypothesis testing with $t$-test. Based on the analysis of learning outcomes data obtained the average experimental class learning outcomes (51.77) is higher than the control class average (39.95). In the normality and homogeneity test it is also known that the experimental class and the control class are normally distributed and homogeneous. After the $t$-test is done, the tcount is 2.33 while the $t$-table is at the significant level of 0.05 is 1.684. Because $t$ count $>t$ table, then HO is rejected and H1 is accepted. So, a conclusion can be drawn that the Thinking Aloud Pair Problem Solving (TAPPS) method is effective on student learning outcomes on the subject of cubes and beams in class 8 of Junior High School.
\end{abstract}

\section{A. LATAR BELAKANG}

Menghadapi era globalisasi yang diiringi dengan perkembangan ilmu pengetahuan dan teknologi (IPTEK) yang sangat pesat, maka peningkatan kualitas sumber daya manusia mempunyai posisi yang strategis bagi kelanjutan dan pembangunan suatu bangsa. Salah satu wadah bagi upaya peningkatan kualitas sumber daya manusia adalah dalam bidang pendidikan. Ada bebrapa indikator dalam peningkatan mutu pendidikan antara lain melalui peningkatan kinerja guru dan peningkatan mutu pembelajaran.
Apabila kita mengamati perkembangan pembelajaran matematika di Indonesia sangat memperhatinkan, karena rendahnya penguasaan teknologi dan kemampuan sumber daya manusia Indonesia untuk berkompetensi secara global. Di tambah lagi dengan masih rendahnya kemampuan anak Indonesia di bidang matematika, mereka beranggapan bahwa pembelajaran matematika itu sulit, serta kurangnya jumlah pengajar yang mengikuti perkembangan matematika. Sebaiknya pihak sekolah, guru, siswa dan pemerhati (yang peduli tentang pendidikan atau ahli pendidikan) 
pendidikan, pemerintah, lebih peduli pada pembelajaran matematika di Indonesia sehingga dapat memberikan dampak yang positif bagi kemajuan pembelajaran matematika di Indonesia.

Berdasarkan observasi peneliti di MTs Darun Najah Al-Falah, diperoleh informasi bahwa banyaknya siswa yang menganggap matematika adalah pelajaran yang sulit dipahami yang membuat nilai hasil belajar masih kurang atau nilai masih dibawah KKM (Kriteria Ketuntasan Minumum) yang ditetapkan sekolah yaitu 70 .

Pembelajaran matematika hendaknya lebih bervariasi menggunakan metode maupun strateginya guna mengoptimalkan potensi siswa. Upaya-upaya guru dalam mengatur berbagai pembelajaran merupakan bagian penting dalam keberhasilan siswa mencapai tujuan yang direncakan. Dalam pembelajaran matematika yang paling penting dilaksanakan adalah proses berpikir. Siswa dilatih mengembangkan kemampuan berpikir logis, analitis, sistematis dan konsisten. Pembelajaran yang berjalan degan baik akan menghasilkan hasil belajar yang baik pula. Agar keaktifan siswa dan hasil belajar matematika mengalami peningkatan diperlukan suatu penerapan metode. Untuk itu metode pembelajaran kooperatif yang dapat menjadikan siswa aktif dengan tujuan agar dapat melatih daya pikir siswa salah satunya ialah metode Thinking Aloud Pair Problem Solving (TAPPS). Metode Thinking Aloud Pair Problem Solving (TAPPS) adalah metode yang menekankan siswa untuk berpikir secara keras (maksudnya dimana siswa harus berpikir sampai menemukan solusi dari permasalahan) dan logis.

Berdasarkan latar belakang masalah di atas, yang menjadi permasalahan dalam penelitian ini yaitu "Bagaimana efektivitas pembelajaran matematika dengan metode TAPPS terhadap hasil belajar siswa kelas VIII SMP".

\section{B. KAJIAN PUSTAKA}

\section{Hasil Belajar}

Hasil belajar dapat dijelaskan dengan memahami dua kata yang membentuknya, yaitu "hasil" dan "belajar". Pengertian hasil menunjukan pada suatu perolehan akibat dilakukannya suatu aktivitas atau proses yang mengakibatkan berubahnya input secara fungsional. Begitu pula dalam kegiatan belajar mengajar, setelah mengalami belajar hasilnya akan berubah dibanding sebelumnya (Subino, 1987:17).

\section{Efektifitas}

Poerwadarminta (1976:266) mengemukakan bahwa efektivitas adalah ada efeknya (pengaruhnya, akibatnya) manjur, mujarab maupun mempan. Efektivitas menunjukan taraf tercapainya suatu tujuan. Suatu usaha dikatakan efektif jika usaha usaha itu mencapai tujuan.

\section{Model Pembelajaran Kooperatif}

Isjoni (2014: 16) mengemukakan bahwa pembelajaran kooperatif adalah suatu model pembelajaran yang digunakan untuk mewujudkan kegiatan belajar mengajar yang berpusat pada siswa, terutama untuk mengatasi permasalahan yang ditemukan guru dalam mengaktifkan siswa, yang tidak dapat bekerja sama dengan orang lain, siswa yang agresif dan tidak perduli pada yang lain.

\section{Thinking Aloud Pair Problem Solving (TAPPS)}

Thinking Aloud artinya berpikir yang diverbalkan, Pair artinya berpasangan dan Problem Solving artinya pemecahan atau penyelesaian masalah. Jadi, Thinking Aloud Pair Problem Solving (TAPPS) dapat diartikan sebagai teknik berpikir yang diverbalkan secara berpasangan dalam menyelesaikan masalah. Saat siswa memecahkan suatu permasalahan, siswa dapat langsung menyampaikan pemikirannya kepada teman sebaya.

\section{Kerangka Berpikir}

Keberhasilan dalam proses belajar mengajar dilihat dari hasil belajar siswa. Banyak faktor yang mempengaruhi keberhasilan belajar siswa, salah satunya adalah metode pembelajaran yang digunakan guru. Penggunaan metode pembelajaran dalam proses belajar mengajar sangat berpengaruh terhadap hasil belajar. Berdasarkan hasil observasi dengan guru matematika kelas VIII di MTs Darun Najah Al-Falah diperoleh bahwa terdapat permasalahan yaitu rata-rata nilai hasil belajar siswa yang dibawah standar yang ditentukan sekolah. Rendahnya hasil belajar siswa ini disebabkan karena kurangnya motivasi belajar siswa, kuranganya pemahaman terhadap soal pemecahan masalah, siswa selalu terpaku pada gurunya, sehingga siswa masih sulit memahami konsep matematika dan aktivitas yang kurang aktif dalam proses belajar mengajar.

Salah satu upaya dalam mengatasi masalah tersebut adalah dengan meningkatkan peran metode pembelajaran. Keaktifan siswa dalam proses pembelajaran sangat sangat dipengaruhi oleh pemilihan metode yang diterapkan oleh guru. Adapun solusi yang ditawarkan dalam mengatasi masalah tersebut adalah dengan menerapkan metode Thinking Aloud Pair Problem Solving (TAPPS).

\section{METODE PENELITIAN}

Jenis penelitian yang digunakan adalah quasi eksperimen dengan rancangan penelitian adalah desain penelitian yang terbagi menjadi dua kelompok yaitu kelompk kontrol dan kelompok eksperimen. Penelitian ini dilaksanakan di MTs Darun Najah AlFalah. Sampel ini diambil dengan teknik sampling purposive adalah teknik penentuan sampel dengan pertimbangan tertentu. Pertimbangan kedua kelas homogen dilihat dari rata-rata nilai ulangan Sistem 
Persamaan Linier Dua Variabel kedua kelas, yakni sebanyak 42 siswa.

Adapun instrument penelitian yakni tes. Soal tes yang digunakan dalam penelitian ini adalah bentuk tes uraian yang bersifat diagnostik untuk mengetahui setiap langkah penyelesaian peserta didik sehingga dapat diketahui adakah peningkatan hasil belajar peserta didik. Tes uraian dalam penelitian ini digunakan untuk mengetahui hasil belajar peserta didik dalam menyelesaiakan soal yang bersifat pemecahan masalah pada materi kubus dan balok. Penelitian ini dilakukan dalam tiga tahap yakni tahap persiapan, tahap pelaksanaan, dan tahap akhir.

\section{HASIL DAN PEMBAHASAN}

\section{Uji Reliabilitas Instrumen Penelitian}

Uji reliabilitas digunakan untuk mengetahui tingkat ketelitian instrumen penelitian. Hasil uji reliabilitas instrumen dengan 20 siswa dan taraf signifikan 5\% maka diperoleh $r_{\text {tabel }}$ sebesar 0,423. Sedangkan hasil perhitungan diperoleh $r_{11}$ sebesar 0,767 . Berdasarkan hasil perhitungan reliabilitas, maka dapat dikatakan bahwa instrumen penelitian dinyatakan reliabel, dimana $r_{11}>r_{\text {tabel }}$.

\section{Hasil Belajar Siswa Kelas Eksperimen TABEL 1}

HASIL BELAJAR KELAS EKSPERIMEN

\begin{tabular}{ccccc}
\hline \multirow{2}{*}{ No } & \multirow{2}{*}{ Interval } & \multicolumn{2}{c}{ Frekensi } & Frekuensi \\
\cline { 3 - 4 } & & $\left(\boldsymbol{f}_{\mathbf{i}}\right)$ & $\boldsymbol{f ( \% )}$ & Komulatif \\
\hline 1 & $25-36$ & 4 & 18,18 & 4 \\
\hline 2 & $37-48$ & 7 & 31,81 & 11 \\
\hline 3 & $49-60$ & 6 & 27,27 & 17 \\
\hline 4 & $61-72$ & 1 & 4,54 & 18 \\
\hline 5 & $73-84$ & 3 & 13,63 & 21 \\
\hline 6 & $85-96$ & 1 & 4,54 & 22 \\
\hline \multicolumn{2}{c}{ Jumlah } & 22 & 100 & \\
\hline
\end{tabular}

\section{Hasil Belajar Siswa Kelas Kontrol}

TABEL 2

HASIL BELAJAR KELAS KONTROL

\begin{tabular}{ccccc}
\hline \multirow{2}{*}{ No } & \multirow{2}{*}{ Interval } & \multicolumn{2}{c}{ Frekensi } & Frekuensi \\
\cline { 3 - 4 } & & $\left(f_{\mathrm{i}}\right)$ & $f(\%)$ & Komulatif \\
\hline 1 & $8-18$ & 2 & 10 & 2 \\
\hline 2 & $19-29$ & 3 & 15 & 5 \\
\hline 3 & $30-40$ & 3 & 15 & 8 \\
\hline 4 & $41-51$ & 9 & 45 & 17 \\
\hline 5 & $52-62$ & 2 & 10 & 19 \\
\hline 6 & $63-73$ & 1 & 5 & 20 \\
\hline \multicolumn{2}{r}{ Jumlah } & 20 & 100 & \\
\hline
\end{tabular}

4. Perbandingan Hasil Belajar Kelas Eksperimen dan Kelas Kontrol

TABEL 3

PERBANGINGAN HASIL BELAJAR

\begin{tabular}{ccc}
\hline Statistik & \multicolumn{2}{c}{ Kelas } \\
\cline { 2 - 3 } Deskriptif & Eksperimen & Kontrol \\
\hline Jumlah siswa & 22 & 20 \\
\hline Maksimum & 94 & 71 \\
\hline
\end{tabular}

\begin{tabular}{ccc}
\hline Minimum & 25 & 8 \\
\hline Rata -rata & 51,77 & 39,95 \\
\hline Median $\left(\mathrm{M}_{\mathrm{e}}\right)$ & 48,5 & 42,94 \\
\hline Modus $\left(\mathrm{M}_{\mathrm{o}}\right)$ & 45,5 & 45,5 \\
\hline Varians & 300,7792 & 230,8921 \\
\hline $\begin{array}{c}\text { Simpangan baku } \\
(\mathrm{s})\end{array}$ & 17,3430 & 15,1951 \\
\hline
\end{tabular}

\section{Uji hipotesis}

Berdasarkan hasil analisa data diperoleh hasil bahwa nilai $t_{\text {hitung }}>t_{\text {tabel }}(2,33>1,68)$ maka $\mathrm{H}_{0}$ ditolak dan $\mathrm{H}_{1}$ diterima sehingga dapat dikatakan bahwa dengan metode pembelaran Thinking Aloud Pair Problem Solving (TAPPS) efektif terhadap hasil belajar siswa pada pokok bahasan kubus dan balok kelas VIII MTs Darun Najah Al-Falah.

Hasil pengamatan sebelum dilakukan pembelajaran dengan metode TAPPS, kegiatan berpusat pada guru. Guru cenderung menstansfer pengetahuan yang dimiliki ke pikiran siswa dan siswa menerima secara pasif dan tidak kritis, adakalanya bisa menjawab tetapi tidak dapat memberikan alasan mengenai jawabannya dan dapat mengunakan rumus akan tetapi tidak tahu asal rumus itu dan mengapa rumus itu digunakan. Ini membuat siswa terlihat tidak tertarik mengikuti proses kegiatan belajar, sebagian besar dari siswa tidak memperhatikan dan lebih senag mengobrol dengan teman-temannya. Sehingga menjadikan siswa kurang aktif.

Kelas eksperimen yang menggunakan metode TAPPS pada setiap pertemuannya melalui tahaptahap pembelajaran yang mana dalam tahapan pertama, siswa mendapatkan permasalahan yang berbeda dengan pasangannya, tahapan kedua mulai mengerjakan permasalahan sesuai peran yang telah disepakati dimana yang sebagai problem solver memaparkan hasilnya kepada listener, dan tahap ketiga setelah selesai mereka bertukar peran untuk permasalahan yang kedua. Metode pembelajaran TAPPS merupakan salah satu metode yang menuntut siswa untuk aktif dan meningkatkan kemampuan penerapan yakni kemampuan yang digunakan dalam menyelesaikan masalah. Terbukti hasil belajar dari posttest kelas eksperimen lebih tinggi dibanding kelas kontrol. Pembelajaran menggunakan metode TAPPS membuat siswa antusias dan tertantang dalam menyelesaikan soal kubus dan balok dalam soal pemecahan masalah secara mandiri dengan bantuan langkah-langkah yang tertera pada LKS. Akan tetapi dalam pembelajaran ini ada saja siswa yang masih kurang percaya diri pada jawabannya, hal ini terlihat dari seringnya siswa bertanya pada guru jawaban tersebut benar atau salah. Sama dengan hal tersebut, saat problem solver memaparkan kepada listener-nya siswa masih kesulitan berkomunikasi dikarenakan siswa belum terbiasa aktif dalam mengemukakan gagasan matematiknya. Selain itu, 
siswa juga belum terbiasa menemukan konsep rumus secara sendiri dikarenakan pada pembelajaran biasanya hanya menerima rumus langsung dari guru. Setelah siswa sudah mulai terbiasa dengan pembelajaran menggunakan metode TAPPS, siswa tertarik dikarenakan merasa bangga pada diri sendiri yang mampu memecahkan masalah dengan sendiri tidak perlu menghafal rumus tetapi memahami penemuannya. Walaupun masih ada beberapa siswa yang belum berpartisipasi aktif, ini merupakan tugas guru untuk selalu memotivasi agar bisa terlibat dalam pembelajaran aktif. Berdasarkan hasil analisis data diperoleh nilai rata-rata hasil belajar siswa kelas eksperimen lebih tinggi dibandingkan dengan nilai rata-rata hasil belajar kelas kontrol, terlihat bahwa siswa pada kelas eksperimen mampu menjawab pertanyaan dengan menggunakan cara penyelesaian, walaupun ada beberapa yang tidak mampu menjawab dengan cara penyelesaian. Hal lain serupa juga pada kelas kontrol hanya ada beberapa yang dapat menyelesaiakan dengan penyelesaian. Nilai tertinggi pada kelas eksperimen adalah 94 dan nilai terendah adalah 25. Sedangkan pada kelas kontrol nilai tertinggi 71 dan nilai terendah 8.

Hal ini sejalan dengan hasil uji hipotesis dimana $\mathrm{H}_{1}$ diterima yang mana rata-rata nilai hasil belajar kelas eksperimen lebih tinggi dibandingkan rata-rata nilai hasil belajar kelas kontrol dengan hipotesis $\mathrm{H}_{1}$ adalah metode pembelajaran Thinking Aloud Pair Problem Solving (TAPPS) efektif terhadap hasil belajar siswa pada pokok bahasan kubus adan balok kelas VIII MTs Darun Najah Al-Falah.

\section{E. SIMPULAN DAN SARAN}

Berdasarkan hasil analisis data dan pembahasan maka dapat disimpulkan bahwa Penggunaan pembelajaran matematika dengan metode TAPPS efektif terhadap hasil belajar siswa kelas VIII MTs Darun Najah Al-Falah. Pembelajaran Metode TAPPS melalui tahapan-tahapan yakni tahapan pertama, siswa mendapat permasalahan yang berbeda dengan pasangannya. Tahapan kedua, dilanjutkan dengan siswa menjalani peran sebagai problen solver dan listener, untuk tahapan ketiga, problem solver menyelesaikan permasalahannya lalu memaparkan kepada listener-nya, kemudian setelah selesai, dilanjutkan untuk permasalahan kedua dengan bertukar peran. Dari hasil analisis uji- $\mathrm{t}$ diperoleh nilai 2,33 > 1,68 $\mathrm{t}_{\text {tabel }}$ yang berakibat $\mathrm{H}_{0}$ ditolak dan $\mathrm{H}_{1}$ diterima. Berarti hasil belajar siswa yang diajarkan menggunakan metode TAPPS lebih baik dibandingkan dengan kelas kontrol yang diajarkan menggunakan metode pembelajaran langsung pada materi kubus dan balok. Walaupun secara individu masih banyak siswa yang mendapatkan nilai dibawah KKM (Kriteria Ketuntasan Minumum).

Adapun saran-saran yang ditemukan oleh peneliti terkait dengan penelitian ini, diantaranya :
1. Berdasarkan hasil penelitian bahwa penggunaan pembelajaran matematika dengan metode Thinking Aloud Pair Problem Solving (TAPPS) efektif terhadap hasil belajar siswa, sehingga pembelajaran tersebut dapat menjadi salah satu alternatif yang dapat diterapkan oleh guru dalam proses pembelajaran untuk meningkatkan hasil belajar matematika siswa.

2. Guru diharapkan membuat perangkat pembelajaran yang memudahkan siswa untuk melakukan proses pembelajaran sehingga proses pembelajaran dapat dilaksanakan dengan lebih baik lagi

3. Bagi siswa hendaknya selalu berusaha untuk memahami sendiri konsep yang disampaikan, memanfaatkan kelompok belajar dengan sebaikbaiknya dan senantiasa melakukan evaluasi untuk mengukur tingkat keberhasilan yang telah dicapai

4. Bagi peneliti selanjutnya diharapkan untuk mencoba menerapkan metode TAPPS pada materi-materi yang lain.

\section{REFERENSI}

[1] Adinawan, M. Cholik dan Sugiyono. (2005). Matematika Smp/Mts jilid 2 untuk kelas VIII. Jakarta: Erlangga.

[2] Arikunto, Suharsimi. (2010). Prosedur Penelitian Suatu Pendekatan Praktek. Jakarta: Rineka Cipta

[3] Barkley, Elizabeth F. (2010). Student engagement techniques : A Handbook For Collage Faculty. USA: PB Printing

[4] Brophy. (1990). Education Psychology. New york: Longman

[5] Gie, The Liang. (2002). Cara belajar yang efiien. Yogyakarta: Pusat Kemajuan Study Yogyakarta

[6] Isjoni. (2014). Cooperatif Learning: Efektivitas pembelajaran kelompok. Bandung: Alfabeta

[7] Klipatrik, Jeremy, Jane Swafford, Bradford Findell. (2010). Adding it up: Helping children learn mathematics. Washington DC: National Academy Press.

[8] Nuharini Dewi. (2008). Matematika konsep dan Aplikasinya untuk Smp/Mts kelas VIII. Siduarjo: Campion Smart.

[9] Purwanto. (2013). Evaluasi Hasil Belajar. Yogyakarta: Pustaka Pelajar

[10] Sudjana, Nana. 2012. Penilaian hasil belajar mengajar. Jatim:SIC

[11] Sugiyono. (2013). Metodologi Penelitian Pendidikan (Pendekatan Kuantitatif, Kualitatif dan $R \& D)$, Cet.X. Bandung: Alfabeta

[12] Suprijono, Agus. (2009). Cooperative Learning Teori Dan Aplikasi Paikem. Yogyakarta: Pustaka Pelajar

[13] Wahyuni, Try. (2008). Matematika konsep dan Aplikasinya untuk Smp/Mts kelas VIII. Siduarjo: Campion Smart 